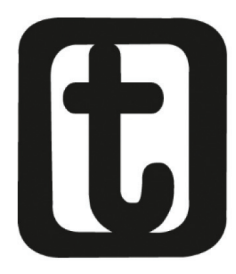

\title{
A UNIVERSALIZAÇÃO DA SEGURIDADE SOCIAL EM QUESTÃO: Ả TRADUÇÃO ANTINÔMICA DOS DIREITOS SOCIOASSISTENCIAIS
}

The universalization social security in question: antinomian translation of social assistance

\author{
Beatriz Augusto Paiva ${ }^{1}$ \\ Eliete Cibele Cirpiano Vaz ${ }^{2}$ \\ Kathiuça Bertollo3 \\ Josiane Biondo 4 \\ Renata Nunes 5
}

\section{RESUMO}

O trabalho que ora apresentamos tem como objetivo problematizar questões relativas ao debate sobre a política pública de assistência social, no contexto do seu reconhecimento como área da seguridade social brasileira. Mais precisamente, pretende instigar a reflexão sobre alguns dos elementos contraditórios que afetam seu desenho como direito não contributivo, cuja

\footnotetext{
${ }^{1}$ Autora: Professora do Departamento de Serviço Social da Universidade Federal de Santa Catarina e integrante do Instituto de Estudos Latino-Americanos (IELA/ UFSC). E-mail: <biapaiva@cse.ufsc.br>.

2 Co-autora: Professora do Departamento do Serviço Social da UFSC. E-mail: <eliete@cse.ufsc.br>

3 Co-autora: Professora do Departamento do Serviço Social da UFSC . E-mail: < kathibertollo@gmail.com >

4 Co-autora:Mestranda da PUCSP. E-mail: < josibiondo@gmail.com>

5 Co-autora: Professora do Departamento do Serviço Social da UFSC.E-mail: <renata.net@gmail.com>
} 
amplitude deve voltar-se para universalização da proteção da seguridade social. É um recorte da produção investigativa que, em longo percurso intelectivo e político, tem se dedicado à análise das políticas sociais na América Latina, privilegiando os temas da assistência social, do financiamento público e do protagonismo popular.

\section{PALAVRAS-CHAVE}

Universalização da seguridade social. Políticas públicas. Assistência social.

\section{ABSTRACT}

The work we now present the aim is to problematize issues relating to public policy debate on welfare in the context of its recognition as an area of Brazilian Social Security. The work we now present the aim is to problematize issues relating to public policy debate on welfare in the context of its recognition as an area of Brazilian Social Security. More precisely intends to instigate reflection on some of the contradictory elements that affect its design as a right non-contributory, whose amplitude should turn to the universalization of social security protection. It is an investigative crop production that in the long intellectual and political journey has been dedicated to the analysis of social policies in Latin America, focusing on issues of social welfare, public funding and the role popular.

\section{KEYWORDS}

Universalization of social security. Public policy. Social assistance.

Submetido: $26 / 3 / 2012$

Aceito:14/5/2012

\section{INTRODUÇÃO}

Este trabalho foi divulgado uma primeira vez por ocasião do debate da II Conferência de Desenvolvimento, promovido pelo Instituto de Pesquisa Econômica Aplicada (Ipea), quando apresenta- 
mos análise versando sobre aspectos e contradições que incidem sobre a política pública de assistência social, no contexto do seu reconhecimento como área da seguridade social brasileira. Nosso ensaio é dividido em duas partes, com a primeira posicionando os termos desse debate, e a segunda trazendo os elementos estruturais e conjunturais que constrangem e sobredeterminam o avanço das políticas sociais na América Latina, em especial a de assistência social.

\section{A POLÍTICA SOCIAL NÃO CONTRIBUTIVA NO HORIZONTE DA UNIVERSALIZAÇÃO}

A Constituição Federal de 1988 (BRASIL, 1988) demarca um novo patamar na relação entre Estado e sociedade, no contexto político brasileiro. Em meio às contradições que assinalaram o período pós-ditatorial, o texto constitucional expressou conquistas importantes no que se refere à construção do sistema de direitos sociais no país, repercutindo, de forma parcial, a consigna popular de defesa de uma seguridade social universal.

Ao estabelecer o chamado tripé da seguridade social, que em tese integraria as políticas de saúde, de previdência e de assistência social, o documento constitucional especifica distinções e respectivos escopos, nos quais a política de saúde incontestavelmente é afirmada como direito de todos e a previdência social destinada mediante contribuição prévia. Já a assistência social, que deve ser prestada independentemente de contribuição, é ainda, ambiguamente, de direito a quem dela necessitar. Certamente, é uma imprecisão problemática do ponto de vista teórico e político legal, porém funcional à lógica focalizadora e restritiva que impera na programática neoliberal.

Dessa forma, a política de assistência social, ao longo de mais de vinte anos de regulamentação, segue semiplasmada no universo da seguridade social, alcançando formalmente o status de política pública, mas constituindo-se de maneira imprecisa e parcial como constructo universalizador do sistema de segu- 
ridade social brasileiro, tarefa evidentemente fundamental, se referida a um projeto de superação do subdesenvolvimento, distinto daquele traçado por Frank $(1973)^{6}$.

O enfrentamento dos mecanismos de reprodução do capitalismo dependente exige como resposta imediata a superação da lógica da superexploração da força de trabalho no âmbito da produção econômica, mas também, e simultaneamente, a elaboração de respostas à desproteção social que marca a condição das maiorias subalternas na América Latina, aquelas mantidas na informalidade e na precarização, traço constitutivo das economias dependentes.

Contudo, as principais versões contemporâneas da política pública de assistência social se inscrevem no centro das engrenagens liberais conservadoras, que se obstinam em impregnar as ações socioassistenciais de forte ênfase particularista, meritocrática e focalista, metamorfoseadas em adjutórios caritativos e compensatórios, desempenhando exclusivamente a função de paliativo, cujo propósito restringe-se à distensão de conflitos sociais e situações extremas de miserabilidade, sob o compromisso ou a retórica de redução das iníquas desigualdades sociais.

O debate político-acadêmico relativo às políticas sociais propaga explícitas censuras ao campo socioassistencial, em parte devido a esse contorno ideopolítico que tradicionalmente distinguiu a composição dessa área, com sua metamorfose para benemerência ou filantropia, bem como sua resistente cercadura clientelista e patrimonialista, próprias das relações políticas oligárquicas no Brasil e continente.

Não obstante o horizonte programático de curto e médio prazos, a realidade da política de assistência social não pode, em absoluto, ser considerada uma estrutura fixa e a-histórica, tal como o pensamento conservador gosta de asseverar.

Há outras dimensões a serem reconhecidas e explicadas. A política socioassistencial, como contributo para uma proteção univer-

\footnotetext{
6 Merecem uma cuidadosa prospecção as análises de Gunder Frank (1973) sobre a dinâmica do desenvolvimento do subdesenvolvimento tão bem caracterizado em suas obras.
} 
sal da seguridade social, pode possuir uma localização inconteste, entretanto com uma ressalva: desde a ruptura com os esquemas meritocráticos e restritivos, deve alimentar-se o potencial político-estratégico da luta popular, tensionada obrigatoriamente no complexo âmbito da socialização da riqueza coletivamente construída e das estruturas de poder político:

A especificidade da política de assistência social pode ser referenciada no âmbito das respostas concretas à grande massa de trabalhadores informais, desempregados e subempregados, àqueles que não são contemplados com as demais políticas sociais e que seguem à margem da proteção social tradicional, alicerçada na contributividade do trabalho formal. Em um projeto distinto, o direito socioassistencial também deve se destinar àqueles que exigem atenção especial e que lutam pelo reconhecimento da magnitude da vida humana e social em suas diferentes manifestações (PAIVA; ROCHA; (ARRARO, 2010, p. 256).

Todavia, a assistência social, progressivamente distinguida de seus vieses estigmatizantes e estigmatizadores, deve voltar-se especialmente para um campo inalcançável pelas demais políticas sociais, pois não é seguro para a força de trabalho formal, mas é proteção aos trabalhadores e suas famílias submetidas à estrutural condição de superexplorados e precarizados. Logo, deve reforçar o protagonismo da população e, de forma simbiótica, assegurar desde medidas de transferência direta não contributiva de valores materiais - a mais ampla seria a garantia de rendimentos - até projetos coletivos que atuem junto aos processos de participação protagônica dos segmentos populacionais a ela vinculados, na perspectiva da disputa real pelo excedente econômico e pela democratização do poder político.

Uma brevíssima contextualização sobre as inflexões e rupturas com esse legado perene permite salientar que no país há em curso uma rudimentar dinâmica de disputa, em que interesses e forças diversas atuam - alguns veladamente - na construção do campo da política pública de assistência social, com sutis potencialidades. Devemos observar que a régua cronológica de regu- 
lamentação do direito à assistência social possui momentos de elaborada construção, desde sua primeira versão em lei em 1991 (vetada inteiramente pelo então presidente Collor de Mello), passando pela aprovação da LOAS - Lei Orgânica da Assistência Social (Lei $n^{\circ}$ 8.742, de 1993), até a recentíssima revisão, sancionada pela presidenta Rousseff (Lei $\mathrm{n}^{0} 12.435$, de 2011), que transforma em lei uma série de dispositivos do Sistema Único de Assistência Social (PNAS/Suas/2004), cuja densidade jurídica era mais fluída, em perenes responsabilidades e mecanismos institucionais, dando nova redação à Loas/2011.

A processualidade sócio-histórica na qual as políticas sociais se movimentam requer análises e reflexões atentas às determinações estruturais e conjunturais, que atravessaram e influíram na efetiva materialização da proteção social em solo nacional e na América Latina. Na esteira dessa análise, destacamos que, nos marcos de sua regulamentação, a assistência social deparou-se com resistências decorrentes do contexto mundial adverso à universalização dos direitos sociais, uma vez que os países em desenvolvimento sofriam inflexões radicais de orientações de caráter neoliberais. De acordo com Couto (2006, p. 140),

[...] na década de 1980 os governos que sucederam assumiram o compromisso de encaminhar as orientações produzidas pelo Consenso de Washington, o que por si só criou uma dupla interpretação: por um lado, houve uma expectativa para o atendimento dos avanços constitucionais, que ampliavam os direitos sociais e o papel do Estado interventor; por outro, a adoção, na formulação da política econômica nacional, das orientações do Consenso de Washington, indicando a diminuição dos gastos nas políticas sociais e na retirada do Estado do campo social.

Outrossim, a herança histórica do atraso político do clientelismo, assistencialismo, paternalismo, que atravessa as décadas neste campo, constitui-se ainda como um dos entraves à consolidação da assistência social como espaço estratégico de protagonismo popular, de fortalecimento e ampliação de direitos. Como salienta Yazbek (1993, p. 21): 


\begin{abstract}
[O social torna-se campo de lutas e de manifestação dos espoliados, o que não significa uma ruptura com o padrão de dominação e de clientelismo do Estado brasileiro no trato com a questão social. Trata-se de uma relação que, sob a aparência de inclusão reitera a exclusão, pois inclui de forma subalternizada, e oferece como benesse o que na verdade é de direito. Mas é importante ter presente que a exclusão não é um movimento unívoco do Estado, pois uma relação que contraditoriamente contém espaço de luta pela conquista de direitos sociais.
\end{abstract}

Esses dois amplos vetores apenas citados aqui - o contexto local e macrossocial restritivo e o legado do atraso ideológico - encontram o século XXI com uma dinâmica ainda paradoxal, mas de sinal diverso. A acolhida tardia da agenda do Sistema Único de Assistência Social (Suas) como política de governo pelo presidente Lula da Silva depara-se com um cenário de expansão econômica ainda tímido, que se agravou com a crise de 2008 e tende a se agravar ainda mais nos próximos anos, frente à ameaça de grande recessão mundial.

Sendo assim, para reconhecermos as potencialidades e as debilidades do processo de concreta tradução do direito socioassistencial no imprescindível sistema universal de seguridade social, é pertinente traçarmos algumas das inflexões que a atual conjuntura esboça.

\title{
3 AS ANTINOMIAS DA REALIZAÇÃO DOS DIREITOS SOCIAIS: O CE- NÁRIO DA DEPENDÊNCIA E DA CRISE PERMANENTE
}

A temporalidade da crise capitalista revela um processo histórico de longa duração, perto de três décadas, a requerer contextualização histórica e apreensão de algumas de suas principais características. Para dimensioná-la bem, vale lembrar que, hoje, em momento de recessão, mas também de expansão, metade da população do planeta vive com menos de um dólar por dia. Assim, pode-se inferir que a questão principal que mobiliza as reflexões acerca do atual modelo político-econômico neoliberal é a seguinte: diante de tantos avanços tecnológicos e científicos, por que os ricos ficam cada vez mais ricos e os pobres ficam cada vez mais pobres? 
Utilizando a categoria de mundialização financeira para particularizar o atual estágio do capitalismo, e para precisar melhor a natureza da crise, Chesnais assim esclarece:

A mundialização financeira nasceu de um processo de interação, ao longo de uns quinze anos, entre o movimento de fortalecimento do capital privado - tanto industrial como bancário - e o crescente impasse das políticas governamentais. O contexto geral é o fim dos 'anos dourados'. Ou seja, embora ela tenha começado a se manifestar em fins da década de 60, a mundialização financeira não pode ser compreendida fora do que os regulacionistas chamam de crise do modo de regulação fordista' e que os marxistas descrevem como ressurgimento, num contexto determinado, de contradições clássicas do modo de produção capitalista mundial, que haviam sido abafadas entre 1950 e a recessão de 1974 (CHESNAIS, 1998, p. 16-17).

Há, nesse contexto, as reminiscências do esgotamento do padrão urbano-industrial, típico do período de expansão capitalista do pós-guerra mundial, aliado a uma grave crise de abastecimento da matriz energética assentada no petróleo, e um esgarçamento da unidade político-mobilizatória dos trabalhadores, no sentido de disputar o excedente, de radicalizar a democracia e de assim aprofundar os mecanismos de universalização dos direitos sociais.

Os anos 1980 foram pródigos na implantação das duras medidas de reversão dessa crise, através da adoção das estratégias neoconservadoras de desregulamentação das relações de trabalho, das relações comerciais e da circulação dos investimentos monetários. Desencadearam-se medidas que vão desde privatizações das empresas estatais, alterações nos sistemas de bem-estar social, formação dos blocos econômicos transnacionais, passando pelas transformações nas modalidades de produção, com a introdução da microeletrônica e dos sistemas computacionais, generalizando as práticas de informatização e de automação, até processos de desregulamentação das estruturas financeiras e comerciais, etc. Parecia que todas as perdas já haviam sido impostas, mas os acontecimentos recentes indicam que o fundo do poço virou nossa morada. 
Como em outros momentos históricos de agudas crises econômicas, a pauperização das massas trabalhadoras permanece crescente mesmo com uma dinâmica de algum virtuosismo econômico que oscilou em ciclos curtíssimos nas últimas décadas, ou seja, simultaneamente, pode-se observar um ciclo expansivo da produção de riquezas, ainda que superficial e à custa da volátil especulação financeira. Ademais, tal virtuosismo não se fez acompanhar de medidas redistributivas em termos do provimento de sistema de direitos voltados às necessidade sociais. Para ir mais longe nesse quadro, deve-se lembrar que o atual estágio de produção e de acumulação de riquezas é, em si mesmo, a principal razão do empobrecimento e do aumento dos processos de exclusão social, contra a qual devem ser empreendidos os esforços em termos de políticas sociais. No momento do aguçamento da crise, o remédio amargo sobre os trabalhadores e suas famílias revela a mesma ação espúria de sempre.

As medidas são incisivas, possuem algum retorno lucrativo de curto prazo - suficiente para a recomposição das condições ótimas de acumulação do capital -, mas por outro lado são produtoras de gravíssimas repercussões do ponto de vista social, a começar pelo crescimento vertiginoso do desemprego estrutural e suas consequências mais deletérias. Presenciam-se cada vez mais condições de desocupação praticamente definitiva, pois é acompanhada do desaparecimento das formas tradicionais de trabalho, em que as colocações não apenas se reduzem ou se tornam mais escassas, mas deixam de existir irreversivelmente, em geral pela substituição do trabalho vivo pelo trabalho morto das máquinas e computadores, resultantes mais concretos das novas tecnologias de comunicação e informação, sem nenhum compromisso com a preservação física daqueles trabalhadores, cujos saberes, habilidades, direitos e necessidades se tornaram descartáveis. Esse processo atinge estratos relevantes da sociedade, incluindo aí trabalhadores jovens ou com experiência consolidada, que se tornam obsoletos ou dispensáveis para a empresa e, o que é pior, para a sociedade. Como bem advertiu Salama (1999, p. 38-39):

A globalização, acompanhada da retirada do Estado, provoca direta e indiretamente uma redistribuição significativa da renda; as desigualdades entre capital 
e trabalho se acentuam à medida que a financeirização das empresas se expande e que os mercados financeiros se tornam 'emergentes' [...]; as desigualdades no interior do trabalho se acentuam entre trabalhadores qualificados e não-qualificados. [...] As desigualdades territoriais se sobrepõem às desigualdades de renda. [...] Longe de provocar o alardeado universalismo, a abertura rápida das fronteiras aumenta a vulnerabilidade [...]. O desaparecimento das fronteiras visíveis produz a eclosão de novas fronteiras invisíveis [...].

As medidas, afinal, resultam em diversificados e ampliados contingentes populacionais em situação de pobreza, agravada pelo desmonte dos sistemas de proteção social - flexisegurança é um gentil conceito - e por uma grande indiferença por parte das elites políticas e econômicas, levando os trabalhadores para uma condição de incerteza e de desamparo social, instalando um gradativo sistema de perdas de garantias e dos vínculos sociais que atavam os indivíduos aos seus grupos sociais, em uma sociedade apartada de um tempo futuro que nunca chega.

O subtexto desse relato demonstra que as históricas estruturas de poder político e econômico no Brasil, e na América Latina em geral, estabelecem padrões ainda mais injustos e assimétricos de usufruto da riqueza coletivamente construída, além de processos híbridos de acesso ao trabalho assalariado, com a expansão do emprego formal, mas também com a intensificação da superexploração, seus vínculos temporários, precários, sem direitos e garantias.

Nas últimas décadas, a sociedade brasileira tem sido tensionada entre os mais altos níveis de desenvolvimento econômico, mas com a perpetuação dos maiores índices planetários de desigualdade social. Os indicadores de concentração de renda são ilustrativos ao revelar tamanha contradição, uma vez que o expressivo Produto Interno Bruto (PIB) no Brasil encobre inversamente os índices de desigualdades assustadores, apontando para a catastrófica distribuição de renda. Dados revelam que no ano de 2009 essa assimetria apresentou certa redução, porém o coeficiente de Gini, que constitui um indicador de concentração de renda, registrou o índice de 0,496 - um dos mais baixos de uma série histórica 
(SILVEIRA; FERREIRA, 2011). Entretanto, o país ainda se localiza entre o que mais concentram renda no globo e, portanto, um dos que se destacam em termos de desigualdade social, fato que evidencia a necessidade de empenho no processo de distribuição da riqueza socialmente produzida e do poder que a sustenta.

Lavinas e Cavalcanti (2007) apresentam, em análise contundente, os impasses da política previdenciária e das políticas compensatórias de transferência de renda - que sustentam a seguridade social brasileira em termos de benefícios monetários. Apesar dos avanços, tais políticas perpetuam os elevados níveis de desigualdade social na sociedade brasileira, apontando tais índices como resultantes da ausência de instrumentos universais, no campo da Seguridade Social, os quais deveriam uniformizar as condições de acesso e padrão de vida dos brasileiros. No entanto, continua deflagrado o modelo contributivo de Seguridade, a despeito do contorno redistributivo do sistema de proteção social deste país.

Os citados autores analisam que a polarização do debate sobre a adequação dos benefícios, sem base contributiva integral, se dá desde a criação do Sistema de Seguridade Social no Brasil, em 1988, formulando que a inovação institucional do sistema de proteção social brasileiro se constituiu de uma dimensão mais universalista, sendo reconhecido o direito à renda monetária e também da garantia da isonomia, igualados os valores do piso dos benefícios previdenciários e assistenciais.

Lavinas e Cavalcanti (2007) ainda asseveram que o Brasil não conta, em seu sistema de proteção social, com um benefício familiar de apoio à infância e adolescência, de amplitude universal, voltados à prevenção contra a pobreza, através da destinação de verba para compensar gastos privados com a educação das crianças e a redução do grau de vulnerabilidade familiar, tal como em muitas democracias europeias. Esse sinalizador revela que a assistência social brasileira, mesmo com os avanços da Loas, está aquém, e muito, das necessidades e potencialidades que a área requer.

Demonstram, ainda, que as políticas (Loas) ou programas (Bolsa Família) de transferência de renda "[...] são instrumentos ex-post de alívio da pobreza [...]” (LAVINAS; CAVALCANTI, 2007, p.250), que requerem comprovação da insuficiência de renda, motivo pelo 
qual não são dirigidos à sustentação das famílias, mas apenas aos comprovadamente pobres. Desse modo,

[...] essas transferências não se constituem, portanto, em direito, ainda que na prática a concessão do BPC tome quase sempre caráter permanente. Contudo, a prevenção, que poderia contrarrestar a pobreza intergeracional, e reduzir significativamente o grau de destituição das famílias mais pobres, ficou de fora do marco regulatório da Seguridade e, por isso mesmo, a universalidade do sistema só alcançou a saúde. Do ponto de vista da garantia de uma renda mínima e de uma atuação preventiva para anular riscos e reduzir sua incidência nos grupos vulneráveis, o sistema de proteção brasileiro continua inacabado, razão pela qual convivemos com níveis elevados de exclusão (LAVINAS; CAVALCANTI, 2007, p. 250).

Nesse sentido, os autores alegam que grande parte das transferências de renda monetária realizadas retorna ao governo através de impostos, ou seja, as contribuições sociais seriam orientadas para fins redistributivos, provisão de bens e serviços universais, como a saúde e também, evidentemente, para cobrir benefícios não contributivos. Na prática, esses recursos financiam outras despesas, por exemplo, benefícios contributivos e despesas de livre alocação do governo, como possivelmente juros da dívida pública. No caso dos benefícios contributivos, sabe-se que parte deles tem impacto redistributivo progressivo significativo, como as aposentadorias rurais (LAVINAS; CAVALCANTI, 2007), mas estes são uma exceção. Há uma contradição inaceitável, decorrente da natureza das fontes de financiamento dos benefícios socioassistenciais. Aqui se reproduz um limite estrutural ao já combalido potencial universalizador da seguridade social brasileira, uma vez que seu conteúdo é a face lunar da permanente usurpação dos trabalhadores. Todos, por meio do consumo de massas, financiam crescentemente não só as políticas sociais numa relação de contributividade oculta, mas todo o Estado brasileiro e seus compromissos financeiros com o capital rentista que, por fim e desde sempre, se apropria de parcelas gigantescas do excedente econômico produzido socialmente.

O desafio de problematizar as perspectivas universalizadoras da seguridade social se depara obrigatoriamente com a desmistifica- 
ção do caráter mitológico (falsa e intencionalmente) atribuído ao projeto de universalização do direito à proteção social por meio apenas das medidas adotadas, sem o exame crítico sobre seus conteúdos econômicos. Assim é que se impõe a pretensão do estudo sobre a composição do orçamento da Seguridade Social, a partir do cotejo com a estrutura econômica e com o sistema tributário como um todo. Tais processos sócio-históricos, embora impregnados de contemporaneidade, se configuram em referências fundamentais na reconstrução dos elementos determinantes da política de financiamento da assistência social e da seguridade social, consequentemente.

$\mathrm{Na}$ atual segunda fase de implantação das reformas neoliberais, a reforma fiscal e a desregulamentação do sistema de seguridade social são as metas que os conservadores neoliberais não desistem de alcançar. Dessa maneira, as necessárias medidas para redução da pobreza seguem no circuito de negociação entre os organismos internacionais, o poder dos monopólios e bancos, o que nos países da América Latina significa a pressão crescente pela redução dos gastos sociais, mesmo com o redirecionamento do investimento para a diminuição da pobreza extrema, agora principalmente em medidas eficientes que fossem capazes de atuar sobre o foco da demanda.

Nesse campo social, a maioria dos países da região negocia as contrarreformas que compõem os programas de ajuste, principalmente nas políticas de educação, saúde e previdência social e, certamente, de assistência social, as quais sofrem permanentes restrições orçamentárias e remanejamentos, que, ademais, têm boa parte dos seus recursos capturados pela iniciativa privada, a partir da lógica de mercadorização dos direitos, pela busca de lucratividade no setor de serviços próprios das políticas sociais. Nesse sentido, observamos ainda um crescimento substancial na América Latina das instituições de ensino privadas, com financiamento direto e indireto do orçamento público, tanto escolas de ensino fundamental e médio como a propagação das universidades e faculdades privadas. Já no âmbito da saúde, as empresas e organizações sociais desmontam o SUS a olhos vistos, com os planos de saúde vivendo grande ascensão, assim como os planos previdenciários privados através dos fundos de pensão. A ânsia pela criação dos fundos de 
pensão complementar para os servidores públicos mantém essa agenda retrógrada para a previdência social do regime integral. Tais tendências privatizadoras seguem atuando nos governos Lula da Silva e Dilma Rousseff, porém de forma positivamente contraditória, ou seja, com espaço e disputa ainda pelo reconhecimento de direitos e de conquistas em consideração.

Recuperando o pressuposto da política social como produto e meio da luta de classes, com a constatação de que ela é parte do processo de disputa do excedente convertido em receitas públicas, nem sempre é factível evidenciar que seu financiamento advém tanto da tributação direta, mas também da indireta, vinculada ao consumo de massa e da renda do trabalho, principalmente e, apenas de forma cosmética, do patrimônio, dos rendimentos financeiros e do lucro apropriado.

Como já ressaltado, pelo impacto dos impostos recolhidos através da atividade da comercialização de mercadorias, ou seja, os incidentes sobre o consumo, fica clara sua alta relevância diante dos demais, pois representam quase $50 \%$ de todos os tributos arrecadados. Sendo assim, sobre eles repousa uma das mais contraditórias características: seu caráter regressivo. Essa regressividade decorre do fato de que, quanto menos ganha o contribuinte, proporcionalmente, mais ele paga em impostos em relação à totalidade da sua renda, pois tudo que recebe é gasto no consumo de gêneros de primeira necessidade, os quais ainda não possuem alíquotas reduzidas e protegidas para redução dos preços dos produtos essenciais ao consumidor. Tal iniquidade não encontra prioridade na pauta de revisão da estrutura fiscal do governo, que insiste na errônea estratégia de desoneração das contribuições na folha de salário, a favorecer diretamente o empresariado, em detrimento do princípio da solidariedade que deve comandar a estrutura de direitos sociais em nosso país.

Além desse desenho particularista, as políticas sociais são intencional e crescentemente subfinanciadas. Esta é certamente outra contradição que demarca a singularidade do capitalismo dependente. Há um deslocamento crescente da renda dos trabalhadores, extraída por meio do pagamento dos tributos, para mecanismos voltados à acumulação, sobretudo, em decorrência dos 
compromissos com a dívida pública dos países latino-americanos. Rosa Luxemburg (1985), no seu belo livro a Acumulação do Capital, publicado em 1921, já havia demonstrado como no Imperialismo os empréstimos externos e o consequente endividamento das nações desempenham um papel extraordinário na dinâmica de acumulação mundial:

O que existe de contraditório na fase imperialista se revela claramente nas oposições características do moderno sistema de empréstimos externos. Eles são imprescindíveis para a emancipação das nações capitalistas recém-formadas e, ao mesmo tempo, constituem para as velhas nações capitalistas o meio mais seguro de tutelar os novos Estados, de exercer o controle sobre as finanças e pressão sobre sua política externa, alfandegária e comercial. Os empréstimos são um meio extraordinário para abrir novas áreas de investimento para o capital acumulado dos países antigos e para criar-lhes, ao mesmo tempo, novos concorrentes; são o meio de ampliar, no geral, o raio de ação do capital e de reduzi-lo concomitantemente (LUXEMBURG, 1985, p. 288).

Como sabido, no atual ciclo de dependência, o endividamento público adquire uma dimensão central no âmbito da dominação burguesa junto ao Estado latino-americano, intensificando a captura dos governos aos interesses da aristocracia financeira que, a partir dos problemas da acumulação, tiveram a capacidade de avançar ainda mais na transformação da profunda crise do capital, em responsabilidade do Estado. É cada vez mais atual a verificação de que "[...] a cada nova tentativa de 'estabilizar a economia' novas dívidas são incorporadas pelo Estado, aprofundando a dependência e impedindo-o de praticar políticas sociais. Com efeito, estas perderam sentido em função da opção recolonizadora da elite na América Latina" (OURIQUES, 2001 p. 38).

Diante dos dados concretos acerca dessa realidade parafraseada pelos mais altos índices de desigualdade e exploração, devemos relembrar que nas últimas décadas se têm experimentado profundas transformações na organização social capitalista. Com isso, reiteramos que a idade dos monopólios (NETTO, 2006) modifica intensamente a dinâmica interna do modelo de 
produção, almejando um só objetivo, a maximização dos lucros 7, assentada muito mais no capital financeiro fictício, que é indiferente às necessidades da classe trabalhadora por direitos sociais e trabalho.

O atual estágio de desenvolvimento capitalista tem sido marcado pela supremacia do capital financeiro sobre o capital produtivo, pela redefinição nas relações entre Estado, mercado e sociedade civil, pela desregulamentação das relações de trabalho e pelo aprofundamento das desigualdades sociais. No atual contexto, de mundialização da economia, destaca-se o protagonismo de grandes grupos industriais multinacionais atrelados a instituições financeiras (através do rendimento de juros) que passam a dirigir o processo de acumulação. Tal movimento, impulsionado por organismos internacionais, captura os Estados nacionais, que assumem papéis contraditórios, mas decisivos, como suporte no processo de acumulação. Ao mesmo tempo em que se configura um mercado mundial unificado, adensa-se o desenvolvimento desigual entre empresas, ramos de produção industrial, nações e interior dos países.

Subjacente à dinâmica da mundialização da economia, há o intenso processo envolvendo os Estados nacionais. No movimento posto pela lógica capitalista em seu atual estágio de crise, sublinha-se mais um redimensionamento do papel do Estado, que passa a ser o fiador e garantidor direto da estatização das dívidas bancárias privadas e manutenção dos seus equivalentes superlucros dos conglomerados capitalistas, por meio da expropriação da riqueza dos trabalhadores na forma do orçamento público e dos gastos sociais. Nesse contexto, o Estado se desnuda como organizador da economia e administrador dos ciclos de crise: uma vez capturado pela lógica capitalista, tem a função de, além de assegurar a reprodução e a manutenção da força de trabalho (ocupada e excedente), regular níveis de consumo em função das necessidades dos monopólios.

7 "O acréscimo dos lucros capitalistas é realizado por meio do controle de mercados, onde o sistema bancário e creditício assumiu expressivo destaque. Corretamente assevera: o capitalismo monopolista recoloca, em patamar mais alto, o sistema totalizante de contradições que confere à ordem burguesa os seus traços mais basilares de exploração, alienação e transitoriedade histórica [...]" (NETTO, 2006, p. 19). 
Concomitantemente, são ressaltados outros grandes desafios aos Estados nacionais, no sentido de garantia de sua soberania, principalmente, nos países dependentes e periféricos. Tal etapa de crise - talvez permanente - tem intensificado a violência cotidiana para as populações empobrecidas e exploradas dessas nações, refletindo de forma aguda no cotidiano de seus povos, que são afetados nas diversas esferas da vida social.

A desconstitucionalização de dispositivos universalistas, redistributivos e outros de natureza social, conforme os interesses empresariais e o patrocínio de medidas fiscais de desvio de receita, a exemplo da Desvinculação de Receitas da União (DRU) proposta pelo governo Cardoso e mantida por Silva, atenderam à agenda política ditada pela lógica de contração macroeconômica. São medidas tradicionais da política econômica neoliberal que favorecem a produção de superávit fiscal, exigência constante da programática neoliberal, que se destina ao pagamento dos empréstimos internacionais e da dívida interna, em posse dos poucos mas poderosos capitalistas.

Todos esses mecanismos fiscais, seja reordenando despesas, seja isentando investimentos, respondem claramente a uma forma específica de a política econômica gerir os interesses públicos, a favor do grande capital. Avançar sobre setores menos prioritários e submeter seus orçamentos a contingenciamentos crescentes e contínuos, de forma a contribuir mais decisivamente no superávit orçamentário, são estratégias usuais de dotação do excedente por sobre medidas redistributivas que têm na seguridade social um terreno fértil, mas ainda árido.

Dados do financiamento público pós-real, decifrado e sintetizado por Salvador (2010), apontam que as despesas financeiras com o pagamento de juros e encargos da dívida quadruplicaram entre 1995 e 2006, com um crescimento de 359,77\%, maior que qualquer outro item no Orçamento da União (excluídos os refinanciamentos).

A participação dos juros no montante do orçamento subiu $74 \%$ e as despesas com amortização da dívida, $160 \%$, enquanto os benefícios previdenciários se mantiveram praticamente constantes, participando com 
$21 \%$ do orçamento, ao passo que as despesas com pessoal reduziram-se em 45\% (SALVADOR, 2010, p. 191).

Como demonstrado nos Grandes Números do Orçamento da União, os valores destinados aos juros e amortização da dívida no período de 2004-2007 (Plano Plurianual do primeiro mandato do governo Lula da Silva) "[...] são duas vezes superiores ao montante do gasto da União com as funções assistência social, saúde, trabalho, educação, cultura, direitos da cidadania, habitação, saneamento, gestão ambiental, organização agrária, desportos e lazer" (SALVADOR, 2010, p. 191).

A superexploração do trabalho, como conceito-chave "[...] que permite decifrar questões-chave da história contemporânea e da forma que a luta de classes assume" (SADER, 2009, p. 30), revela não só como se dá a extração do valor nos países periféricos nesse período histórico marcado pela desregulação e pela deslocalização dos capitais, mas também singularmente agora nos países centrais, desde a globalização neoliberal, que corresponde à "[...] constituição de um mercado de trabalho no plano internacional marcado pela precariedade e pela mobilidade acentuada dos capitais" (SADER, 2009, p. 30).

Essa programática impõe a conjugação de medidas destinadas à criação de novas formas de valorização do capital, em especial a circulação de fluxos globais especulativos de curto prazo, possíveis pelas conquistas dos novos sistemas de comunicação e informação, gerando uma liberalização sem precedentes para a valorização financeira, com os custos da flutuação transferidos, ainda mais, para a classe trabalhadora.

A destinação do excedente para os ganhos do capital encontra no orçamento brasileiro um observatório modelar, quando examinamos os números referentes ao refinanciamento da dívida pública federal, que traduz o quantum de emissão de novos títulos, no manejo contábil de rolagem da dívida. Cerca de metade do orçamento fiscal e da seguridade social tem sido destinada aos compromissos com os credores financeiros do governo. Salvador (2010, p. 193) analisa: "A rolagem da dívida, apesar do efeito apenas contábil, tem consequências econômicas, pois implica despesas que o governo tem que liquidar semanalmente via emissão de 
novos títulos que precisam ser submetidos a um "teste de credibilidade' junto ao mercado financeiro".

A submissão política aos ditames do grande capital financeiro é a nova face da frágil soberania dos governos latino-americanos, sintoma e causa da impotência das estratégias de construção dos direitos sociais nessa simbiose entre a dependência estrutural e a planificação neoliberal.

Assim, as sucessivas ondas modernizantes impulsionadas de fora para dentro e aplicadas sem reservas a partir do Estado latino-americano não somente são incapazes de resolver os problemas da desigualdade e da injustiça, senão que são precisamente a causas pelas quais estas características se perpetuam sem solução definitiva em curto prazo (PAIVA; OURIQUES, 2006, p. 172).

As facetas discrepantes da lógica de financiamento da Seguridade Social provocam um número equivalente de contestações enfáticas e de defesas reticentes. Em jogo, acumulam-se os desafios para se garantir recursos suficientes e sistemáticos para o aparato de proteção social brasileiro, cujas estratégias articuladas, até o momento, estão sob a mira das disputas políticas tradicionais.

Tanto a base de financiamento, através das contribuições sociais, como as vinculações obrigatórias aos fundos específicos têm sofrido críticas e modificações substantivas, embora em doses homeopáticas, o que não tem impedido perdas reais, ano a ano, na composição dos recursos sociais. Entretanto, a iniciativa de reforma tributária que tramita no congresso brasileiro em conformidade com as diretrizes do Fundo Monetário Internacional (FMI) pretende operar a desvinculação praticamente total entre as receitas e despesas governamentais nas áreas sociais.

Independentemente da hibridez e da fragilidade do atual sistema de financiamento da Seguridade Social, é importante enfatizar que apenas os recursos advindos das contribuições sociais são insuficientes para financiar qualquer sistema que se anuncie universal. A resistência aos cortes orçamentários nas políticas sociais, em contraposição à ampliação dos recursos ao permanente socorro do mercado financeiro, que suporta a flagrante transferência de recursos sociais para a valo- 
rização do capital demarcam o centro da polarização ético-política na qual se inscreve a disputa pela universalização da seguridade social.

\section{CONSIDERAÇÕES FINAIS}

Em síntese, a natureza antipopular dos processos políticos determinados pela lógica da dependência no Brasil se reproduz na desigualdade do acesso ao excedente, dirigindo-os para as minorias privilegiadas, enclausurando a população superexplorada num grande vácuo político-institucional, com direitos fracamente definidos. Por essa razão, a tentativa de ampliar a seguridade social para além do vínculo com a condição de assalariamento formal parece urgente, embora ainda longe de ampla efetivação. Setores importantes da sociedade brasileira estão de fora do alcance do sistema, ainda que seja a grande maioria da força de trabalho economicamente ativa, dentre os trabalhadores rurais, do setor informal, temporários, subempregados, enfim, estruturalmente precarizados.

Essa tendência tipifica toda a América Latina e, crescentemente, o mundo capitalista central, como ficou demonstrado (MARINI, 2000 apud VALENCIA, 2009, p. 113) já havia concluído: “[...] generaliza-se em todo o sistema, inclusive nos centros avançados, o que era um traço distintivo (ainda não operativo) da economia dependente: a superexploração generalizada do trabalho".

O pacto interelites, que dita o processo de ajuste e estabilização econômica, tem promovido a difusão das reformas antipopulares agora, em 2011, nos países europeus, desde a periferia - Grécia e Portugal -, mas também na Inglaterra e na França. Na esteira de um processo muito desigual de barganha política e de disputa distributiva, entre empresários, trabalhadores, corporações e entes federativos, a banca sai sempre vitoriosa ${ }^{8}$.

8 "Enquanto a economia americana patina e não apresenta uma recuperação consistente, os grandes bancos dos Estados Unidos tornam-se ainda maiores, com retomada dos lucros e incorporação de instituições que faliram nos últimos anos. Conforme levantamento do Brasil Econômico, os seis maiores conglomerados bancários totalizam ativos em volume $15 \%$ superior ao registrado em 2007, quando os efeitos da crise do subprime ainda não tinham se intensificado. A maior parte desses bancos, protagonistas da crise que ganhou escala global, foi socorrido pelo governo americano, que injetou trilhões de dólares no sistema financeiro para incentivar o crédito e para comprar ativos conside- 
O processo de acumulação no contexto da mundialização favorece em muitas circunstâncias a reatualização de marcas do neocoIonialismo e do intervencionismo militar tão presentes na história das crises sistêmicas. De tal modo, a nova organização do capital mescla tradicionais relações sociais construídas a partir de uma burguesia nacional, que assume uma orientação antidemocrática (ao tomar exclusivamente seus interesses de classe), assim como parece ser destituída de sentimento nacionalista, o que contribui para assentar o aprofundamento das relações de dependência com países ditos desenvolvidos.

Nessa perspectiva, Darcy Ribeiro, em sua obra O Dilema da América Latina (1978), nos auxilia a compreender a complexa configuração da estrutura de poder produzida pelo processo histórico, em que o atraso das nações latino americanas está intimamente ligado à associação de nossa classe dominante às agências internacionais de exploração, mantendo e impondo uma ordenação social desigualitária e permanente. Destarte, tanto a ordenação interna das nações subdesenvolvidas quanto a regulação imposta pelos países hegemônicos a essas nações compõem o fenômeno da violência estrutural, afetando de forma aguda as condições de vida dos seres sociais, que sofrem direta e indiretamente as refrações dessa dinâmica.

Logo, o desafio na universalização dos direitos sociais requer tanto o deciframento das determinações econômicas que afetam singularmente o campo das políticas sociais quanto um compromisso político de novo tipo com sua superação, ao lado de que há um reconhecimento verdadeiramente transformador a ser feito: o novo desenho essencialmente latino-americano para as políticas sociais - para além da reprodução dos modelos impostos desde fora - exige a unidade entre as ações e serviços não contributivos (que a assistência social absorveu) com o protagonismo das forças populares e seus interesses, jamais visibilizados e acatados neste sul político e geográfico.

rados tóxicos que estavam em poder das instituições financeiras. Agora, passados mais de dois anos da eclosão da crise, alguns conseguiram até dobrar de tamanho" (RIBEIRO, 2011). 


\section{REFERÊNCIAS}

BRASIL. Constituição Federal 1988. Constituição da República Federativa do Brasil. Brasília: Senado Federal, 1988.

BRASIL. Lei $n^{\circ}$ 8. 742, de 7 dezembro de 1993. Dispõe sobre a Assistência Social e dá outras providências. Disponível em: <http:// www81.dataprev.gov.br/sislex/paginas/42/1993/8742.htm>.

BRASIL. Lei $n^{\circ} 12.435$, de 6 de julho de 2011. Altera a Lei no 8.742, de 7 de dezembro de 1993, que dispõe sobre a organização da Assistência Social. Disponível em: <http://www.planalto.gov.br/ccivil_03/_Ato2011-2014/2011/Lei/L12435.htm>.

CHESNAIS, François. Introdução geral. In: CHESNAIS, François (Coord.). A mundialização financeira: gênese, custos e riscos. São Paulo: Xamã, 1998.

COUTO, Berenice Rojas. O Direito Social e a Assistência Social na sociedade brasileira: uma equação possível? 2. ed. São Paulo: Cortez, 2006.

FRANK, Gunder. America Latina: subdesarrollo o revolución. México: Era, 1973.

SILVEIRA, F. G.; FERREIRA, J. Equidade Fiscal no Brasil: impactos distributivos da tributação e dos gastos sociais. Colaboração de Luciana Acioly et al. Brasília: IPEA, maio 2011. (Comunicado IPEA, n. 92). Disponível em: <http://www.ipea.gov.br/portal/images/ stories/PDFs/comunicado/110519_comunicadoipea92.pdf>.

LAVINAS, Lena; CAVALCANTI, André. O Legado da Constituição de 1988: é possível incluir sem universalizar? Carta Social e do TrabaIho, Campinas, n. 7, set./dez. 2007.

LUXEMBURG, Rosa. A acumulação do capital. São Paulo: Nova Cultural, 1985. (Coleção Os Economistas).

NETTO, José Paulo. Capitalismo monopolista e Serviço Social. 5. ed. São Paulo: Cortez, 2006.

OURIQUES, Nildo. Estado e Políticas Sociais na América Latina. In: NOGUEIRA, Francis Mary Guimarães. Estado e Políticas Sociais no Brasil. Cascavel: Edunioeste, 2001. 
PAIVA, Beatriz; OURIQUES, Nildo. Uma perspectiva latino-americana para as políticas sociais: quão distante está o horizonte? Katálysis, Florianópolis, v. 9, n. 2, p. 166-175, 2006.

PAIVA, Beatriz; ROCHA, Mirella; CARRARO, Dilceane. Participação popular e assistência social: contraditória dimensão de um especial direito. Katálysis, Florianópolis, v. 13, n. 2, 2010. Disponível em: <http://www.scielo.br/scielo.php?script=sci_arttext\&pid=S1414-49802010000200012\&lng=pt\&nrm=iso >. Acesso em: 18 set. 2011.

RIBEIRO, Ana Paula. Wall Street: grandes bancos estão ainda maiores nos EUA. Carta Capital. Redação, 9 jun. 2011. Disponível em: $<$ http://www.cartacapital.com.br/economia/grandes-bancos-estao-ainda-maiores-nos-estados-unidos/>. Acesso em: 9 jun. 2011.

RIBEIRO, Darcy. O dilema latino-americano. Petrópolis: Vozes, 1978. SADER, Emir. Ruy Mauro, intelectual revolucionário. In: SANTOS, Theotonio; SADER, Emir (Coords.); MARTINS, Carlos Eduardo; VALENCIA, Adrian Sotelo (Orgs.). A América Latina e os desafios da globalização. Rio de Janeiro: PUC/Rio; São Paulo: Boitempo, 2009.

SALAMA, Pierre. Novas formas de Pobreza na América Latina. In: GENTILI, Pablo (Org.). Globalização excludente. Petrópolis: Vozes; Buenos Aires: CLACSO, 1999.

SALVADOR, Evilásio. Fundo público e Seguridade Social no Brasil. São Paulo: Cortez, 2010.

VALENCIA, Adrian Sotelo. A reestruturação do mundo do trabalho: superexploração e novos paradigmas da organização do Trabalho. Uberlândia: EDUFU, 2009.

YAZBEK, Carmelita. Classes subalternas e a assistência social. São Paulo: Cortez, 1993. 